\title{
Transient Information Adaptation of Artificial Intelligence: Towards Sustainable Data Processes in Complex Projects
}

\author{
Nicholas Dacre ${ }^{a}$, Fredrik Kockum ${ }^{\circ}$, \& PK Senyo ${ }^{\circ}$ \\ ${ }^{a}$ University of Southampton Business School, Southampton, UK nicholas.dacre@southampton.ac.uk \\ b University of Southampton Business School, Southampton, UK f.h.e.Kockum@soton.ac.uk \\ c University of Southampton Business School, Southampton, UK p.k.Senyo@soton.ac.uk
}

\begin{abstract}
Large scale projects increasingly operate in complicated settings whilst drawing on an array of complex data-points, which require precise analysis for accurate control and interventions to mitigate possible project failure. Coupled with a growing tendency to rely on new information systems and processes in change projects, $90 \%$ of megaprojects globally fail to achieve their planned objectives. Renewed interest in the concept of Artificial Intelligence (Al) against a backdrop of disruptive technological innovations, seeks to enhance project managers' cognitive capacity through the project lifecycle and enhance project excellence. However, despite growing interest there remains limited empirical insights on project managers' ability to leverage Al for cognitive load enhancement in complex settings. As such this research adopts an exploratory sequential linear mixed methods approach to address unresolved empirical issues on transient adaptations of $\mathrm{Al}$ in complex projects, and the impact on cognitive load enhancement. Initial thematic findings from semi-structured interviews with domain experts, suggest that in order to leverage Al technologies and processes for sustainable cognitive load enhancement with complex data over time, project managers require improved knowledge and access to relevant technologies that mediate data processes in complex projects, but equally reflect application across different project phases. These initial findings support further hypothesis testing through a larger quantitative study incorporating structural equation modelling to examine the relationship between artificial intelligence and project managers' cognitive load with project data in complex contexts.
\end{abstract}

Keywords: Transient Information, Adaptation, Artificial Intelligence, Al, Sustainable, Data Processes, Complex Projects, Project Management, Project Failure, Project Success, Cognitive Load, Mega Project, Intelligent Systems, Cockpit Design, Megaproject.

Cite this Paper

Dacre, N., Kockum, F., \& Senyo, PK. (2020). Transient Information Adaptation of Artificial Intelligence: Towards Sustainable Data Processes in Complex Projects. British Academy of Management, Manchester, UK. https://dx.doi.org/10.2139/ssrn.3813559 


\section{A Backdrop of Dynamic Complex Projectification}

In 2007 Crossrail secured a government project for the construction of a new railway line spanning London (Day, 2017). The project was issued a completion date of 2018 at a total cost of $£ 14.8 \mathrm{bn}$. However, due to project deficiencies largely emanating from systems and information failures, project completion has been delayed until 2022 with a reviewed upwards budget of $£ 18.25 b$ (Cheetham, Moffatt, Addison, \& Wiseman, 2019; Sweet, 2019). A 23\% increase in spending. The UK's Universal Credit project (Bush, Templer, \& Allen, 2019), a governmentled consolidation project of disparate benefit payments supported by legacy technologies and information systems (Omar, Weerakkody, \& Sivarajah, 2017), was announced in 2010 with a completion date of 2017 at a cost of $£ 2 b n$.

The new system was initiated in order to modernise and streamline a complex system of benefits, however complex information and software problems have delayed project completion until 2024 with a spiralling budget exceeding $£ 12 \mathrm{bn}$. More recently, the UK HS2 infrastructure project has been announced, linking London with Birmingham, Manchester, and Leeds via high-speed rail with a project budget of $£ 56 \mathrm{bn}$ and an initial completion date of 2026 (Charlson \& Dunwoody, 2018). It is now anticipated to complete in 2040 at a cost of $£ 106 b n$ due in part to a lack of understanding and comprehension of the complexity of the project. These examples follow a global trend, where megaprojects have an estimated failure rate as high as $90 \%$ (Lenfle \& Loch, 2017). However, small and medium projects are not immune to project failure with an estimated $80 \%$ of projects failing to wholly meet their planned objectives (APM, 2015).

Despite these indicative high failure rate in projects, the increasing projectification of services, products, innovations, and processes in organisations and society is a major contributor to the UK economy. The practice contributes around $£ 156.5 \mathrm{bn}$ of annual GVA and provides employment for an estimated $£ 2.13 \mathrm{~m}$ full-time equivalent workers (APM, 2019). Therefore, when projects fail, this can have catastrophic effects on the economy, society, and the environment.

The concept of Artificial Intelligence (Al) as coined by John McCarthy during the Dartmouth Conference in 1956 (Andresen, 2002), reflects an increasing 
convergence of technology, innovation, and human reasoning. Although $\mathrm{Al}$ has been conceptualised, adapted, and re-appropriated, it is through the onset of recent incremental yet salient technological and systems developments that the field is permeating into a range of sectors and industries. For example, $\mathrm{Al}$ is making further in-roads into Sports (Chu, Shih, Chou, Ahamed, \& Hsiung, 2019), Construction (Juszczyk, 2017), Entertainment (Meena, Jingar, \& Gupta, 2020), Healthcare (Jiang et al., 2017), and Project Management (Dacre, Senyo, \& Reynolds, 2019; Wauters \& Vanhoucke, 2016). The project management field is showing promise in cognitive adaptations, and transient information, where access to data, retention, and execution is important across different stages of the project lifecycle.

Project data attributes can span a number of different salient dimension, such as complex, structured, unstructured, volume, velocity, and variety (Whyte, Stasis, \& Lindkvist, 2016). Project managers operating in increasing challenging contexts, require further insights to manage complex project data (Pedroza-SN, 2019). Therefore, leveraging nascent disruptive technology attributes such as Al which may on one hand aid project management cognitive processes, however the rate of development is increasingly proving challenging for project practitioners (Bhavsar, Shah, \& Gopalan, 2019; Meharwade et al., 2019). Elements of technological advancements, and innovation are spreading at a faster rate than practitioners are able to fully benefit from their implementation. Furthermore, organisations are aware of a number of nascent innovations (i.e. innovations which are gaining popularity but yet to be fully developed for project purposes), however have limited capacity and ability to adapt to these dynamic technologies.

Cognitive load, defined as one's ability to process and apply knowledge (Paas, Tuovinen, Tabbers, \& Van Gerven, 2003), or knowledge-based attributes may span tacit and explicit issues which include knowledge management, transfer, coordination, sharing, access, and intelligence attrition throughout the project lifecycle. These play a part in the overall process of projects and portfolio management (Lin, Müller, Zhu, \& Liu, 2019; Wei \& Miraglia, 2017). Hence the need for project research to investigate the role of $\mathrm{Al}$ with complex data, to offer a model 
for project organisations to best leverage these for project excellence (Sirisomboonsuk, Gu, Cao, \& Burns, 2018).

\section{Research Outline}

This research in development employs an exploratory sequential mixed method. This approach supports the analysis of emergent themes from qualitative data. These themes are then used to guide the development of a large-scale quantitative survey for analysis and discussion (Creswell, 2013; Denzin \& Lincoln, 2005; Grbich, 2012). Mixed methods are particularly adept in uncovering emergent themes, exploring complex ideas, and understanding complex issues (Creswell, 2013; Reynolds \& Dacre, 2019). An initial round of qualitative empirical data has been collected through a number of semi-structured interviews with domain experts. This has helped guide early thematic interpretations of transient information adaptions of artificial intelligence in complex projects.

Semi-structured interviews were recorded with individual consent and adhered to ethical guidelines. Respondents were able to terminate interviews at any point. Interviews were transcribed as close as possible to the interviews in order to capture the depth of the insights and were cross-checked against any additional contextual notes acquired during the interview. Coding of the interviews followed a structured iterative six phase approach, which includes data familiarisation, initial coding, searching for themes, defining and naming themes, and producing a summary data report (Braun \& Clarke, 2006).

\section{Brief Discussion}

Megaprojects are indicative of extreme levels of complexity (Davies, 2019). Brookes et al. (2017) state the nature of the long-term duration of mega-projects offers a novel way of researching the multiple temporalities within long-term projects. Project managers in these environments have a greater degree of confidence for failure than success. Furthermore, historical examples of successful megaproject, such as the Manhattan and Apollo project remain few and far between (Flyvbjerg, 2017). Hence project managers have a larger data set of dependant failure rates than success factors. As such, modern mega projects 
which rely on increasingly complex data-points for design, definition, planning, implementation and control, require comparative levels of cognitive processing and accuracy.

Humans are generally very good at managing cognitive load efficiently (Paas et al., 2003; Sweller, 2011). In part this is what has led to the development of modern society. Our ability as a species to acquire knowledge, construct critical thoughts, and apply our knowledge and skills in constructive ways. However, increasing cognitive loads can lead to process paralysis (Kirsh, 2000). For example a trained pilot is able to cogently recognise a number of key patterns in ensuring flight conditions are optimal and sustained across an array of data-points (Tudoreanu, 2016). However, in sever conditions such as an emergency for which the pilots have no prior training, this leads to a cognitive overload, where the individual's ability to recognise, assimilate, and process information in a cogent way, becomes diminished as the velocity and variety of data increases (Puma, Matton, Paubel, Raufaste, \& El-Yagoubi, 2018). This is why cockpit design is fundamental to ensuring the safety of the plane. By focusing on cognitive load and transient information processes mediated through intelligent systems, aeroplane manufacturers enhance the ability and capacity of pilots to remain cogent with fastpaced changing dynamics. Project managers operating in complex megaprojects, may face a similar cognitive overload which can diminish their ability to make cogent decisions, leading to process paralysis. The concept of $\mathrm{Al}$ in this research study may thus be framed as a cognitive load enhancer through transient information adaptations in complex projects. Therefore the aim of the study is to further elaborate and test this overarching hypothesis.

\section{Work in Progress}

A second round of qualitative based interviews to further refine early insights will take place with 25 domain experts or project professionals. These will be targeted based on experience, qualifications, and their role throughout the project lifecycle. These second round of interviews will adopt the initial qualitative approach, in that to extract rich meaning from the data in context, interviews will be scheduled preferably in person, however where this is not feasible using digital facilitated 
communication platforms. Each interview will be broadly themed and guided by the overarching research enquiry, with a duration between 1 and 2 hours.

The third phase of the empirical data collection will involve the design and implementation of an online survey guided by the emergent themes from the qualitative approach. The survey will focus on examining mediating variables. The survey will be distributed to 400 domain experts. Survey questions will initially establish key indicators, such as rank, role, responsibilities, experiences, specific area of expertise, projects managed, industry, salary range, number of projects managed, failed projects, reasons, successful projects, and constraints. This is not an exhaustive list but illustrates key indicators. The survey will be managed through the use of the Qualtrics survey software. Quantitative data collection will follow established academic ethical guidelines at all times to ensure informed consent and uphold the safety and anonymity of the interviewees, respondents, and individuals undertaking the research process. The results of the empirical survey will then be fully analysed using Structural Equation Modelling (SEM).

\section{References}

Andresen, S. L. (2002). John McCarthy: father of Al. IEEE Intelligent Systems, 17(5), 84-85. http://dx.doi.org/10.1109/MIS.2002.1039837

APM. (2015). Conditions for Project Success. APM, Princes Risborough, United Kingdom. APM. (2019). The Golden Thread. APM, Princes Risborough, United Kingdom.

Bhavsar, K., Shah, V., \& Gopalan, S. (2019). Business Process Reengineering: A Scope of Automation in Software Project Management Using Artificial Intelligence. International Journal of Engineering and Advanced Technology (IJEAT), 9(2).

http://dx.doi.org/10.35940/ijeat.B2640.129219

Braun, V., \& Clarke, V. (2006). Using thematic analysis in psychology. Qualitative research in psychology, 3(2), 77-101. http://dx.doi.org/10.1191/1478088706qp063oa

Brookes, N., Sage, D., Dainty, A., Locatelli, G. \& Whyte, J. (2017). An island of constancy in a sea of change: Rethinking project temporalities with long-term megaprojects. International Journal of Project Management, 35, 1213-1224. https://doi.org/10.1016/j.jproman.2017.05.007

Bush, L., Templer, M., \& Allen, K. (2019). How can Universal Credit help parents move out of poverty? 
Charlson, A., \& Dunwoody, A. (2018). Briefing: Embedding circular thinking in a major UK infrastructure project. Paper presented at the Proceedings of the Institution of Civil EngineersEngineering Sustainability. http://dx.doi.org/10.1680/jensu.17.00070

Cheetham, M., Moffatt, S., Addison, M., \& Wiseman, A. (2019). Impact of Universal Credit in North East England: a qualitative study of claimants and support staff. BMJ open, 9(7). http://dx.doi.org/10.1136/bmjopen-2019-029611

Chu, W. C.-C., Shih, C., Chou, W.-Y., Ahamed, S. I., \& Hsiung, P.-A. (2019). Artificial Intelligence of Things in Sports Science: Weight Training as an Example. Computer, 52(11), 5261.

Creswell, J. W. (2013). Research design: Qualitative, quantitative, and mixed methods approaches: Sage publications.

Dacre, N., Senyo, PK., \& Reynolds, D. (2019). Is an Engineering Project Management Degree Worth it? Developing Agile Digital Skills for Future Practice. Engineering Education Research Network, Coventry, UK. https://dx.doi.org/10.2139/ssrn.3812764

Davies, A. (2019). Project Management for Large, Complex Projects. APM, Princes Risborough, United Kingdom.

Day, G. (2017). UK skills crisis: learning lessons from Crossrail for staffing future infrastructure projects. Paper presented at the Proceedings of the Institution of Civil Engineers-Civil Engineering.

Denzin, N. K., \& Lincoln, Y. S. (2005). The Sage handbook of qualitative research (Third ed.): Sage. http://dx.doi.org/10.2307/2076550

Flyvbjerg, B. (2017). The Oxford handbook of megaproject management: Oxford University Press.

Grbich, C. (2012). Qualitative Data Analysis: An Introduction (2nd ed.): SAGE Publications. Jiang, F., Jiang, Y., Zhi, H., Dong, Y., Li, H., Ma, S., . . Wang, Y. (2017). Artificial intelligence in healthcare: past, present and future. Stroke and vascular neurology, 2(4), 230-243.

http://dx.doi.org/10.1136/svn-2017-000101

Juszczyk, M. (2017). The challenges of nonparametric cost estimation of construction works with the use of artificial intelligence tools. Procedia engineering, 196, 415-422.

https://doi.org/10.1016/j.proeng.2017.07.218

Kirsh, D. (2000). A few thoughts on cognitive overload. http://dx.doi.org/10.3406/intel.2000.1592 
Lenfle, S., \& Loch, C. (2017). Has megaproject management lost its way? The Oxford handbook of megaproject management, 21. https://doi.org/10.1093/oxfordhb/9780198732242.013.2

Lin, L., Müller, R., Zhu, F., \& Liu, H. (2019). Choosing suitable project control modes to improve the knowledge integration under different uncertainties. International Journal of Project Management, 37(7), 896-911. http://dx.doi.org/10.1016/j.ijproman.2019.07.002

Meena, M. R., Jingar, M. P., \& Gupta, S. (2020). Artificial Intelligence: A Digital Transformation Tool in Entertainment and Media Industry. Our Heritage, 68(1), 4661-4675.

Meharwade, R., Dsouza, J., Gupta, A., Prabha, N., Sivakumar, A., Sarlashkar, G., . . Mallapur, S. (2019). Artificial intelligence and machine learning based project management assistance. In: Google Patents.

Omar, A., Weerakkody, V., \& Sivarajah, U. (2017). Digitally enabled service transformation in UK public sector: A case analysis of universal credit. International Journal of Information Management, 37(4), 350-356. https://doi.org/10.1016/j.jijnfomgt.2017.04.001

Paas, F., Tuovinen, J. E., Tabbers, H., \& Van Gerven, P. W. (2003). Cognitive load measurement as a means to advance cognitive load theory. Educational psychologist, 38(1), 63-71. https://doi.org/10.1207/S15326985EP3801_8

Pedroza-SN, A. (2019). Potentials of Blockchain application in BIM: An effective solution to complex data management and reliability of information on big AEC projects. University College London.

Puma, S., Matton, N., Paubel, P.-V., Raufaste, É., \& El-Yagoubi, R. (2018). Using theta and alpha band power to assess cognitive workload in multitasking environments. International Journal of Psychophysiology, 123, 111-120. https://doi.org/10.1016/j.ijpsycho.2017.10.004

Reynolds, D., \& Dacre, N. (2019). Interdisciplinary Research Methodologies in Engineering Education Research. Engineering Education Research Network, Coventry, UK. https://dx.doi.org/10.2139/ssrn.3812769

Sirisomboonsuk, P., Gu, V. C., Cao, R. Q., \& Burns, J. R. (2018). Relationships between project governance and information technology governance and their impact on project performance. International Journal of Project Management, 36(2), 287-300.

https://doi.org/10.1016/j.jproman.2017.10.003

Sweet, R. (2019). Damned if they did: A defence of Crossrail. Construction Research and Innovation, 10(2), 32-38. http://dx.doi.org/10.1080/20450249.2019.1621583

Sweller, J. (2011). Cognitive load theory. In Psychology of learning and motivation (Vol. 55, pp. 37-76): Elsevier. https://psycnet.apa.org/doi/10.1016/B978-0-12-387691-1.00002-8 
Tudoreanu, M. E. (2016). Interface for augmenting spatial orientation of pilots via low cognitive load, peripheral vision. Paper presented at the Proceedings of the International Working Conference on Advanced Visual Interfaces. http://dx.doi.org/10.1145/2909132.2909279

Wauters, M., \& Vanhoucke, M. (2016). A comparative study of Artificial Intelligence methods for project duration forecasting. Expert Systems with Applications, 46, 249-261.

http://dx.doi.org/10.1016/j.eswa.2015.10.008

Wei, Y., \& Miraglia, S. (2017). Organizational culture and knowledge transfer in project-based organizations: Theoretical insights from a Chinese construction firm. International Journal of Project Management, 35(4), 571-585. https://doi.org/10.1016/j.ijproman.2017.02.010

Whyte, J., Stasis, A., \& Lindkvist, C. (2016). Managing change in the delivery of complex projects: Configuration management, asset information and 'big data'. International Journal of Project Management, 34(2), 339-351. https://doi.org/10.1016/j.ijproman.2015.02.006 